\title{
PROBLEMS IN THE ADMINISTRATION OF COMMON TRUST FUNDS
}

\author{
RODMAN WARD*
}

Aside from such a basic legal difficulty as common law and statutory prohibitions of the commingling of trust funds, and the later, rather unexpected but fortunately only temporary harassment of heavy federal income taxation, the development and acceptance of the common trust fund idea by banks and trust companies has been impeded by practical problems, some of which are merely an exaggeration of present problems of trust institutions, and not essentially different from those with which they already are faced. Some, however, are entirely new and are the result of the necessary attempt to make the operation of this method of mass investment coincide with the tenets of trust law which have been developed for centuries to meet problems arising out of individualized trusteeship.

Problems which fall into the first of these two classes, those not essentially different, are to a large extent managerial. Their solution has been or will have to be solved from a business point of view. They are problems in efficiency and their solution should not affect the beneficiary in so important a fashion as would the solution of legal problems. Upon it does to a certain extent depend the answer to the question whether common trust funds may help to alleviate the general economic distress of trust institutions. If you will grant for the sake of argument that mass investment of trust funds properly carried on has, inherently, advantages for certain types of trusts chiefly deriving from the opportunity for increased diversity of investment, there yet remains the question whether a trustee can afford to practice this mass investment. Unless it can be carried on without additional expense over present methods, it is obvious that its use will not spread so rapidly. If it simplifies the work and decreases the expense of trust administration not only will there be increasing pressure from trust institutions behind any tendency toward its wider acceptance, but beneficiaries of trusts will be helped for at least two additional reasons. There will be less pressure for higher rates of fees for trustees and the larger and more highly organized trust institutions will be less loath to accept smaller trusts which are now, in many cases, actually an expense to them.

Such managerial problems, however, hold little interest to many people. Many of

-A.B., 1924, Williams College. Trust officer, Equitable Trust Company, Wilmington, Delaware. Member of the Special Committee on Common Trust Funds of the Trust Division of the American Bankers Association. 
them have to do with bookkeeping. An explanation of them would be generally incomprehensible without detailed descriptions of ordinary bookkeeping methods now adopted generally by banks and trust companies. Suffice it to say here that those persons who have had experience in the operation of common trust funds believe that none of this class of problem is insurmountable, in fact none should be really disturbing to the well organized and properly equipped trust institution operating under an intelligently drawn statute or correctly drawn trust instruments.

The problem of investment management and control with which trust institutions are now faced is, under a common trust fund, greatly decreased since there are so many fewer units of investment to be watched. There is a danger of future trouble to the trustee of such a fund however which arises out of the seemingly necessary but severe restriction imposed by the Regulation of the Federal Reserve Board requiring elimination from a fund of all securities not currently proper for trust investment before new money may be admitted thereto or cash may be withdrawn therefrom.

Many states, for example, require that a mortgage shall not be greater than a certain percentage of the value of the property on which it is secured in order for a trustee properly to invest in it. The trustee of a common trust fund might purchase a mortgage with a five year maturity which was proper in every respect at the time of purchase but which, through general declines in real estate values, represented at a later date a greater percentage of its security than permitted. This mortgage would then have to be eliminated from the common trust fund before new trusts might begin participation therein or before withdrawing trusts might receive payment in cash for their interest in the fund. Such a mortgage might not be salable at a fair figure. The only course left open to the trustee then is to segregate it, to freeze it for the benefit of the then participants in the fund and liquidate it later as best he can.

Not only does the possibility of there existing a succession of such frozen assets bring the threat of extensive bookkeeping, but it would also promise considerable embarrassment to the trustee and annoyance to the beneficiary. Some persons with the recent depression years vividly in mind do not see the possibility of avoiding, at some dark time in the future, a great deal of difficulty trom this kind of thing.

To the writer, the only practical solution to this problem lies in taking the greatest care at the time investments are made. Mortgages, for so many years thoroughly liquid, have shown their dangers at certain times. Therefore they cannot form as important a part in the portfolio of a common trust fund as they might of an individual trust. What mortgages are taken for it should be considered carefully in the light of the last seven years' experience, with regard for the individual credit of the mortgagor and for the safety factor of regular amortization or curtailment. Some leeway should be allowed between the amount of the mortgage and the amount which would be permitted under the trust investment law. Mortgages for a short term should be taken if possible.

The situation with regard to bonds purchased for the fund is not so dangerous if 
their liquidity is high, if they have a broad market. With them, however, the policy should be as conservative, relatively speaking.

The result of such a policy may not be to keep a fund absolutely clean in the event of some future financial cataclysm but it should go very far toward avoiding serious difficulties in the operation of a fund. Another result, which is unfortunate but seemingly necessary, is that the income yield of a properly run common trust fund will be lower than that which might be obtained for a good-sized individual trust. However it must be remembered that the participants in a fund will be small trusts, under $\$ 25,000$ generally speaking, and that smaller aggregations of capital, as a rule, cannot expected to fare as well as may larger ones.

In this connection it is interesting to notice that the New York common trust fund statute forbids the inclusion of any real estate mortgage in a fund.

A certain amount of fear has been expressed that common trust fund investment would tend to make the value of a trust fluctuate more than it would if it were invested individually. There does not seem to be any logical reason why this result would be reached in the average case. In fact in many cases of individual trusts the opposite effect should be attained. A trust of ten thousand dollars cannot as a practical measure have diversified investment in itself. Among fifty or a hundred such trusts there are bound to be some for which an unfortunate investment will be made. Perhaps half of one such trust will be placed in a security which depreciates considerably. This one trust will suffer an impairment by a large percentage although the fifty trusts may, on the average, retain their unimpaired value. The fact that there is appreciation in forty-nine trusts will be cold comfort to the beneficiaries of the fiftieth. If the same money had been pooled in one fund, no one beneficiary would have been harmed.

There may be a small amount of emphasis psychologically placed on what fluctuation there is. Normally the remainderman of a terminated trust which has been invested in a common trust fund is paid in cash. Normally the remainderman of another trust which has been invested individually will to a large extent receive securities in kind. In the first case the remainderman sees he is getting so many dollars and he knows there were originally a certain number of dollars in the trust. He has a direct comparison. In the second case the comparison is less pointed, or, if the general securities market is low at that time, it is easier for him to understand where and why depreciation has occurred.

Persons interested in common trust funds have also foreseen a problem in connection with them arising out of a necessary delay in the distribution of a trust which has participated in a fund when the termination of the trust is brought about by death or some other unpredicable event. Under the regulations of the Board of Governors of the Federal Reserve System and for important practical reasons, units of participation in a fund may not be redeemed except at a previously determined date. Likewise for practical reasons such redemption dates should not occur too frequently. Consensus of opinion and experience both seem to show that quarter-annually is 
often enough. In some cases this would delay distribution of a trust for almost three months from its theoretical termination.

However, in the case of almost any trust there is so much formality to be gone through-accounts to be stated, securities to be transferred, and so forth-that distribution cannot nowadays be made very expeditiously in any event. In practice it is found that the case is not common where excessive delay is attributable to the investment in a common trust fund. Provision may be made in the plan or declaration of trust governing the common trust fund for intermediate and irregular valuation and redemption dates to be determined by the trust investment committee of the trust institution so that in exceptional cases or when considerable amounts are awaiting redemption or investment, this delay can be cut down considerably.

Such an intermediate valuation date is in itself quite troublesome however, not so much because of the determination of values necessary, but chiefly because there must at the same time be made an accrual or allocation of income on the various investments held by the fund.

The best rule from the standpoint of the trustee seems to be to stick to the regular, periodically recurring dates unless transactions are in sufficient volume to make a change worthwhile. It is not believed that this will cause unjustifiable hardship for any beneficiary, particularly since there does not seem to be any reason why an advancement against the value of the terminated trust could not be made him.

There is an interesting class of problems, in addition to those touched on above, which largely arise out of the attempt to fit this new method of trust investment into a law which has developed to fit individual trust investment. It seems that the proper solution of these may best be found in the courts or in new statute law designed to fit the circumstances. If the use of common trust funds spreads, if they become the ordinary thing instead of the extraordinary, there will undoubtedly be developments and clarifications of now established legal principles to suit them.

The Federal Reserve regulations, the New York State common trust fund statute and the regulations of the New York State Banking Department have on some points given an indication of the way authority looks on these. Future revisions of these will give a clearer view since the revision will show the trend or direction of thought.

One such problem, which has quite properly been avoided in the Federal Reserve regulation because the laws of the various states are so far from agreement on its application to individual trusts, has to do with the amortization of premiums over par paid for purchased securities with a fixed maturity. While the rule as to amortization in any one state may be clear in its application to individual trusts, it is not clear in its application to common trust funds.

There is naturally no problem in those jurisdictions where such amortization is forbidden or is not required. Elsewhere, however, it is a question which needs careful study. Probably the only satisfactory answer is to be had in a statute.

In the first place it may be clarifying to point out that a unit of participation in a 
common trust fund strictly speaking has no par value and in no sense has a fixed maturity. Therefore the principal of amortization cannot properly be applied to the cost price of such a unit purchased by a trust.

An explanation of the peculiarity of the problem must first be given. Since this cannot be a general discussion of the various laws on and methods of amortizing such premiums, it will be confined to the most general rule. In application, this is that if a trustee pays one thousand and ten dollars for a one thousand dollar bond due exactly ten years from the purchase date, in order to avoid wasting the principal of his trust estate and favoring the life beneficiary to the disadvantage of the remainderman the trustee must withhold, out of the interest received on that investment, an amount each time interest is collected which is calculated to reimburse principal for the ten dollar premium in full by the time of the maturity of the bond, in other words fifty cents each six months. He must withhold this from income and pay it into principal.

However, let us consider what happens in the case of such a purchase made for a common trust fund. We shall say that at the time of such a purchase there are nine trusts each participating to an equal extent in the fund. Shortly thereafter another trust begins participation in the fund to an extent equal to each of the first nine by paying into the fund its pro rata share of the then value of the fund. The particular bond, as bonds will, has meanwhile fluctuated in value. It has gone contrary to its long range expected trend and is currently worth one thousand and twenty dollars. The newly participating trust has paid at that rate for the one-tenth equitable ownership in that bond which it has acquired. Manifestly it is absurd to say that the life beneficiary of this newly participating trust shall suffer and the remainderman of it shall benefit each six months to the extent of one-tenth of fifty cents out of the interest on this bond. Fifty cents to that trust has no meaning and bears no relationship to the indirect but nevertheless actual cost to it of the premium on the bond. Accurately speaking (begging the question of even the theoretical accuracy of this method of amortization), proper amortization of the premium on that bond for that trust should be at twice that rate, disregarding the lapse of time since purchase and the consequently reduced period to maturity.

At each subsequent time that new trusts are admitted to participation in the fund, there would probably be an entirely new basis for accurate amortization insofar as the new trusts are concerned. Obviously therefore this ordinary method of amortization has no exact meaning and no reasonable basis in equity for a common trust fund because the ownership of the bond is constantly shifting at varying prices.

According to one method of classification, there are two types of common trust funds, commonly called legal and contract funds. The legal fund is one which is authorized by statute as a method of investment for any trust fund. It can be roughly considered as an addition to the statutory list of authorized investments for trustees. It is generally accepted that in a state which by law requires amortization of bond 
premiums in trusts the terms of which do not otherwise specify, only a statute can eliminate or modify this requirement for a legal common trust fund. ${ }^{1}$

The situation with respect to amortization in a contract common trust fund is somewhat different. The term "contract common trust fund" or "contract fund" must be first explained. It indicates the type of fund which is not authorized for general use by statute and the authority for participation in which must be found in the terms of the various participating trusts. For this type statutes might also eliminate or modify the usual amortization requirements. However such requirements can more readily be changed in many instances by the combination of the terms of the plan or declaration of trust which governs the contract fund and of the terms of the participating trusts which permit investment through such a fund.

If the common trust fund declaration of trust specified a method of amortization or that there shall be no amortization, and if the trust instrument governing a participating trust specifies that the trustee thereof may invest in and in accordance with the terms of that particular common trust fund, the difficulty is eliminated without the help of statute.

A question occurs to the writer to which the answer is not clear and which should be considered.

Suppose a common trust fund declaration of trust as above, and suppose a will which authorizes the trustee of the trust established thereunder to invest without statutory limitation and specifically in common trust funds established by it for the use of its trusts. The will is silent as to amortization; the state law requires it; and the particular common trust fund, the terms of which prohibit amortization, is established after the death of the testator. Would the terms of the will permit the trustee to invest in the fund?

If the will specifically provided that the trustee thereunder might invest in preferred

${ }^{2}$ Although present opinion takes the view stated above, an argument to the contrary has been made which runs along the following lines: If the common fund were held by a third party as trustee and the participations issued to the trust institution as trustee for its several trusts, there would be no duty upon the third party to amortize bond premiums. The duty to amortize is imposed to insure fair dealing between suecessive beneficiaries, Restatement, Trusts (1935) $\$ 239$, but in the hypothetical situation, the cestui que trust of each participation would be the trustee of the participating estate, not the life tenants and remaindermen of that estate. The status of the trustee as beneficiary of the common trust would not differ from that of an individual holding a participation in his own right. Does the fact that the common fund is not held in trust by a third party as trustee but by the same corporate entity which is trustee of the participating trusts change this situation? Certainly it is arguable that it does not. To reach the contrary result requires a disregard of the distinct capacities in which it holds the common fund and the participating interests therein, a disregard which is not dictated by practical considerations. However, even though the trustee, as trustee of the common fund, is under no duty to amortize, there remains the question whether it is required to amortize the income received by it as trustee of each participation. If the participation is regarded as a distinct security and not merely as evidence of an undivided intercst in the securities comprising the fund, then there is no basis for amortization since the participation, as such, is not a depleting asset, even though some of its constituent parts may be. That the participation may be regarded as a distinct security is evidenced by the terms of the New York Act which provides that no "person having an interest in any estate, trust or fund shall have or be deemed to have any ownership in any particular asset or investment of such common trust fund." N. Y. BANkinc LAw, \$100-c(2).

It may be granted that the foregoing line of reasoning is legalistic in character. It is reinforced, however, by the practical difficulties of applying the rule of amortization to the common fund situation which are diseussed in the text and the lack of any real danger to remaindermen resulting from its non-application. 
stocks of $X$ Corporation, the trustee undoubtedly might invest in a class of preferred stock which is issued by $X$ Corporation after the death of the testator. However, if the testator had attempted to incorporate in his will by reference the terms of an as yet unwritten document, he obviously could not do so. In other words the question more broadly is whether a testator can grant to his trustee authority to invest in a common trust fund to be established under a declaration of trust which is not in existence at the time of the execution of the will. Again the answer may depend upon whether a participation in a fund is an investment in itself or an investment, by means of a certain method, in the many different securities which comprise the fund.

This question is highly theoretical and any attempt at its answer is beyond the scope of this paper, but it is pointed out here as an indication of a problem which may have to be considered in certain types of common trust funds.

Complete statutory relief from amortization may not be available. What then can be done? Is there a substitute method which avoids at least to some extent the absurdities of the ordinary method and which the legislators or the judiciary may approve? Also is there a method which can be applied so that trusts requiring amortization and trusts forbidding amortization may both participate in the same fund?

These questions have been explored at considerable length in New York State. Attorneys, surrogates, officials of trust institutions and the State Banking Department there have cooperated in attempting to find a more equitable and practical method. The result is to be found in the Regulations of the New York State Banking Department governing the establishment and operation of common trust funds.

Instead of establishing a fixed and continuing rate of amortization for each bond purchased at a premium, the rate of amortization for each bond is successively fixed at and by the appraisals of the bond which are determined for the successive valuations of the fund. From and after the first valuation date after the purchase of a bond, the amount paid for the bond originally has no bearing whatsoever on its rate of amortization. The make-up of the fund, from the standpoint of participating trusts, is constantly changing. Therefore, in effect says this method, the rate of amortization should be constantly changing so as to reflect more closely the cost of the bond to the trusts at any one time participating.

This method is somewhat more cumbersome than the ordinary way, admittedly, although it is not believed to be so much so as to be impracticable. As said above, its adoption in New York State is the result of a great deal of careful attention. However, the writer has recently applied it to a few, theoretical situations. While the test is far too incomplete to be conclusive, the results would lead him to doubt that any more accurate or equitable result is obtained by this method than by the standard method commonly used in ordinary trusts.

Whatever method of amortization is used, if it is to affect all of the trusts participating in the fund, the appropriate amount of income is carried to principal within 
the fund just as it would be in an individual trust and the book or carrying values of the affected bonds may be reduced as ordinarily. However, if some of the participating trusts require amortization of premiums and some forbid it, the only way available is to carry all of the income from the fund to the participating trusts as if there were no amortization. Then, on the separate books of each trust which may require it, that part of the income which is determined to be appropriate is applied to principal and the cost value of the units of participation held by that trust is reduced accordingly.

This too is somewhat cumbersome and, if it is necessary, would naturally decrease the benefits to be obtained by a trust institution from the use of a common trust fund.

So far as now can be judged, amortization is to be avoided in the operation of these funds if it is in any way possible. Peculiarly there is not so much necessity for it as there may be in an individual trust account. Whereas in the latter case the investment portfolio may remain to a considerable extent fixed during the continuance of the trust, yet the securities in which a trust account has an interest through its participation in a fund will tend to change constantly. Particularly is this true if the fund is either increasing or decreasing in size. The trust is constantly acquiring an interest in the new investments which the fund is making and likewise is disposing of a part of its interest in old investments to the new participants. Over a period these changes are being made with the money market in different conditions, with bonds sometimes high priced and sometimes low priced. The result is that each such trust will average its costs much more than any one small trust invested individually would. The discounts will all the more completely balance the premiums.

Even with a fund static as to size, the fact that it is a large pool of investments will normally indicate a diversification of maturities not to be had in a small trust. For this reason too, investments in which the trust is interested will be made in varying states of the money market.

Another problem in the operation of common trust funds is likewise a problem of the rights of successive beneficiaries in a participating trust, except that it is the question of allocation of that which is, legally, income.

Again the law in different states is far from unanimous, so the explanation will have to be based on what is the most common rule. Normally, in the absence of contrary specification in a trust instrument, when the income beneficiary of a trust dies, his estate is entitled to all income due and collected, to all interest accrued to the date of his death and to all dividends declared payable to stockholders of record prior to his death on securities held in his trust. A remainderman or a succeeding income beneficiary is entitled to the balance.

By what appears to be necessary regulation, so as to avoid opportunities for inequities between participating trusts and the taking of unfair advantages through the exercise of hindsight, withdrawals from a fund may only be made on previously determined dates. Withdrawal from a fund of the interest of a trust therein cannot be made, therefore, on or as of the date of a death which has terminated a life interest 
in that trust. For other reasons, too, this appears essential. Too frequent withdrawals from a fund, each of which requires a complete and accurate valuation of it, would render the fund impracticable.

For various reasons it appears that it is practical to determine the ownership of the income of the fund, as a general rule, only on periodically recurring and previously determined valuation dates.

From this it is clear that the general rule as to the rights of successive beneficiaries to income referred to above cannot, practically speaking, be strictly applied to income from a common trust fund. If the portfolio of the investments of a fund were all in interest bearing securities and did not in any respect change between valuation dates, the income of the fund would be accruing at an even rate from day to day and the exact legal result could be obtained by considering that the income distributed from the fund accrued as bond interest does. However investments bearing one rate of interest are sold and with their proceeds are purchased securities with a different rate. Discretionary contract funds will hold stocks in their portfolios.

In other words, the rights to income as between successive beneficiaries can only be determined strictly in accordance with law if, after the death of such a beneficiary and as of the date of that death, each accruable item of income in the fund is accrued and if all other items are apportioned. This is hardly practical because the number of investments in a fund will be great.

It must be remembered that the participation of no one trust in a fund can be large. Therefore it is believed that substantial justice will be done, and justice to within a very few dollars, if the only practical solution be applied. This is that, no matter the make-up of the fund from the investment point of view, the income from the fund which is distributed to trusts be considered to accrue at an equal rate from day to day in determining the rights of successive beneficiaries to it.

The two problems presented above appear to the writer to be the most serious, from the point of view of legal theory, with which the common trust fund is faced and to which no thoroughly satisfactory answer has yet been given. Each results from an attempt to impose on a new subject law which has developed around an old one. Each is subject to easy correction, if necessary, through statute.

Furthermore each suggests the same basic question which will probably only be answered at some distant time in the future and if the common trust fund idea continues to spread and to be adopted in practice. To what extent is the investment of a trust in units of participation in a common trust fund similar to a purchase of a security and to what extent is it the purchase of an interest in each of the basic securities which are held by the fund? The more the theory of this new form of investment tends toward the former, the more simple and easy of administration will it be. But the more it tends toward the latter, the more complicated its administration and the more difficult and retarded its development will be. 